\title{
A Comparison of Dexmedetomidine and Midazolam for Sedation in Gynecologic Surgery Under Epidural Anesthesia
}

\author{
Yongxin Liang ${ }^{\mathrm{a}, \mathrm{b}}$, Miaoning $\mathrm{Gu}^{\mathrm{b}}$, Shiduan Wang ${ }^{\mathrm{a}}$, Haichen $\mathrm{Chu}^{\mathrm{a}, \mathrm{c}}$
}

\begin{abstract}
Background: To evaluate the efficacy of dexmedetomidine (DEX) versus midazolam (MDZ) for sedation during gynecologic surgery under epidural anesthesia.
\end{abstract}

Methods: This was a randomized, double-blinded study. The study was designed to accrue 121 patients scheduled for oophorectomy or/and hysterectomy, to test for equivalence in sedation during surgical procedures, defined as less than a $10 \%$ difference in the proportion of patients with a Ramsay Sedation Scale (RSS) score of $<$ 3 (1 - 6 scale).

Results: One hundred forty patients were enrolled, with 124 patients evaluable for outcomes: 63 received midazolam, while 61 received dexmedetomidine. Dexmedetomidine produced comparable sedation and satisfaction scores to midazolam, but it was not associated with respiratory depression. Bispectral index (BIS) values were significantly less with dexmedetomidine than midazolam at the same RSS score $(\mathrm{P}<0.05)$. Compared with Group MDZ, heart rate (HR) of Group DEX was lower at each time point in the surgery, and there were no significant differences in mean artery pressure (MAP) between the two subject groups.

Conclusions: Dexmedetomidine for sedation in gynecologic surgery under epidural anesthesia is safe and feasible. Compared with midazolam, it not only provides a satisfactory and arousable seda-

Manuscript accepted for publication December 5, 2011

${ }^{a}$ Department of Anesthesiology, The Affiliated Hospital of Qingdao University Medical College, Qingdao 266000, People's Republic of China

${ }^{\mathrm{b}}$ Department of Anesthesiology, Nan Fang Hospital, South Medical University, Guangzhou 510515, People's Republic of China

${ }^{\mathrm{c} C}$ Corresponding author: Haichen Chu, Department of Anesthesiology, The Affiliated Hospital of Qingdao University Medical College, Qingdao, 266000, People's Republic of China.

Email: liangzi66@hotmail.com

doi: $10.4021 / j \operatorname{cs} 107 \mathrm{e}$ tion but without respiratory depression.

Keywords: Dexmedetomidine; Midazolam; Sedation; Epidural anesthesia; Bispectral index

\section{Introduction}

During epidural anesthesia in patients undergoing gynecologic surgery, intravenous sedative-analgesia drugs are often administered to make patient comfort eliminating mental stress and visceral reaction, to improve surgical conditions, and to prevent recall of unpleasant events. Midazolam combined with opioids are commonly used for anxiolysis and/or analgesia. It is essential that patients be responsive and capable of maintaining their airway without assistance. Unfortunately, this combination of drugs can cause respiratory depression, placing the patient at risk for hypoxemia. In a study of volunteers, Bailey et al reported that the combination of midazolam and fentanyl increased the frequency of hypoxemia in 11 of 12 subjects and produced apnea in 6 of 12 subjects [1].

Dexmedetomidine (DEX) is an alpha-2 adrenoceptor agonist that, although similar in site of action to clonidine, is a pure agonist rather than a partial agonist at the receptor level [2]. Its affinity for binding to the alpha-2/alpha-1 receptor is 1300:1 compared with 39:1 for clonidine [3,4]. It has potent sedative analgesia-sparing properties [5-11]. At therapeutic doses, dexmedetomidine is not associated with respiratory depression despite often-times profound levels of sedation [5, 12]. Because of these properties (sedation, analgesia, and respiratory-sparing), dexmedetomidine might prove useful for sedation during epidural anesthesia. In this study, dexmedetomidine was compared with midazolam for sedation during epidural anesthesia in patients undergoing gynecologic surgery.

\section{Materials and Methods}

This double-blinded (patient and assessor), randomized comparison study was conducted with the QingDao University 
Table 1. The Patients' Characteristics and Perioperative Data.

\begin{tabular}{|c|c|c|c|}
\hline Variable & $\begin{array}{l}\text { MDZ group } \\
(n=63)\end{array}$ & $\begin{array}{l}\text { DEX group } \\
(n=61)\end{array}$ & P Value \\
\hline Age (y) & $50 \pm 6$ & $49 \pm 4$ & 0.391 \\
\hline Weight (kg) & $68 \pm 3$ & $67 \pm 8$ & 0.947 \\
\hline $\begin{array}{l}\text { ASA Grade } \\
1 \\
2\end{array}$ & $\begin{array}{l}52(97 \%) \\
11(3 \%)\end{array}$ & $\begin{array}{l}53(97 \%) \\
8(3 \%)\end{array}$ & 0.504 \\
\hline RASS of three or above $(\mathrm{n}, \%)$ & $61(97 \%)$ & $61(100 \%)$ & 0.162 \\
\hline Operative time (min) & $101 \pm 30$ & $102 \pm 41$ & 0.879 \\
\hline Total fentanyl dose (mg) & $54 \pm 11$ & $17 \pm 7$ & 0.016 \\
\hline Bradycardia (n, \%) & 3 & 11 & 0.020 \\
\hline Hypotension (n, \%) & 10 & 8 & 0.664 \\
\hline Respiratory depression (n, \%) & 8 & 0 & 0.004 \\
\hline Recovery time (min) & $45 \pm 8$ & $42 \pm 5$ & 0.495 \\
\hline Mean patients' satisfaction score & 8 & 9 & 0.779 \\
\hline Mean surgeons' satisfaction score & 9 & 9 & 0.834 \\
\hline
\end{tabular}

Data are given as mean \pm standard deviation or as percentage.

Institutional Review Board approval and written, informed consent, 140 ASA physical status I and II patients aged 37 to 65 years and scheduled for epidural anesthesia for surgery of oophorectomy or/and hysterectomy, were enrolled. Those with hepatic, renal, cardiovascular, respiratory, neurological diseases, or gynecologic cancer which was proved by intraoperative pathology were excluded in this study.

The sedation drug was prepared by an anaesthesiologist who did not participate in patient management or data collection. Either dexmedetomidine $1 \mu \mathrm{g} / \mathrm{kg}$ or midazolam 0.1 $\mathrm{mg} / \mathrm{kg}$ was mixed with normal saline to a total volume of 20 $\mathrm{mL}$ and this was given to the attending anaesthesiologist for administration. Both preparations were clear solutions and patients, medical and nursing staff and data collectors were blind to the allocated drug.

Hydroxyzine $50 \mathrm{mg}$ and atropine $0.5 \mathrm{mg}$ were administered intramuscularly (IM) 30 minutes before anesthesia as our routine premedication. On arrival at the operating theatre, a 22-gauge intravenous cannula was inserted. Lactated Ringer's solution was infused at $10 \mathrm{~mL} / \mathrm{kg} / \mathrm{hr}$ for the first hour, followed by $5 \mathrm{~mL} / \mathrm{kg} / \mathrm{hr}$. An epidural catheter was inserted into $\mathrm{L}_{1}-\mathrm{L}_{2}$ or $\mathrm{L}_{2}-\mathrm{L}_{3}$ interspaces using the median approach and the hanging-drop or the loss-of-resistance technique. After aspiration for blood or cerebrospinal fluid, a $3 \mathrm{~mL}$ test dose of $2 \%$ lidocaine was injected to rule out subarachnoid placement of the catheter. Epidural anesthesia (EA) was induced by epidural administration of $0.1 \mathrm{~mL} / \mathrm{kg}$ of a mixture of $1.5 \%$ lidocaine and $2 \mu \mathrm{g} / \mathrm{mL}$ fentanyl, as a loading dose to achieve a sensory level up to dermatome T8. 4 to $6 \mathrm{~mL}$ of the same mixture was administered epidurally every 45 minutes. Anesthesia level was checked with cold sensation after 15 minutes. When anesthesia level became adequate for surgery, patients were randomly assigned by computer-generated randomization schedule to the midazolam (MDZ) group or the dexmedetomidine (DEX) group. The $20 \mathrm{~mL}$ solution of study drug was infused at $60 \mathrm{~mL} / \mathrm{h}$ for the first $10 \mathrm{~min}$ (loading dose: DEX $0.5 \mu \mathrm{g} / \mathrm{kg}$, MDZ $0.05 \mathrm{mg} / \mathrm{kg}$ ), followed by $10 \mathrm{~mL} / \mathrm{h}$ (maintenance dose: DEX $0.5 \mu \mathrm{g} / \mathrm{kg} / \mathrm{h}$, MDZ 0.05 $\mathrm{mg} / \mathrm{kg} / \mathrm{h}$ ). On achieving the targeted Ramsay Sedation Scale (RSS) [13] scores (3 - 5), surgery was begun. The infusion was stopped after the full $20 \mathrm{ml}$ had been given. Ephedrine 6 $\mathrm{mg}$ or atropine $0.5 \mathrm{mg}$ was given intravenously in the event of hypotension (systolic blood pressure reduced by $30 \%$ compared with the baseline or systolic blood pressure less than $90 \mathrm{mmHg}$ ) or bradycardia (HR $<50$ times/min). If respiratory depression (the oxygen saturation decreased to less than 95\%) occurred, mask pressure ventilation was given; inadequate analgesia was treated with intravenous injection 


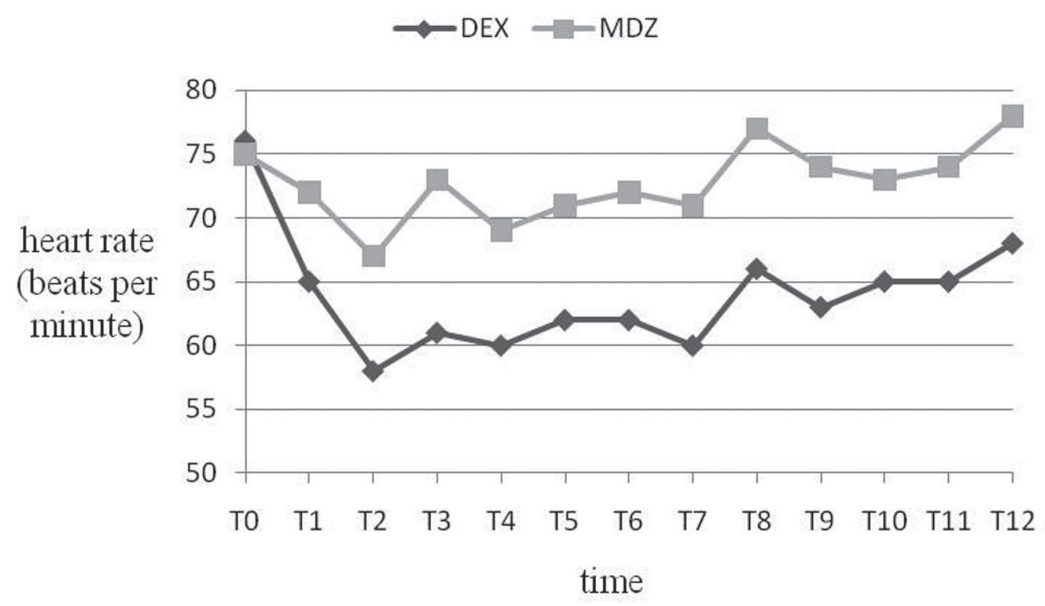

Figure 1. Heart rate (HR, beats/min) variables during study drug infusion $\left(T_{0}-T_{7}\right)$, the end of surgical procedures $\left(T_{8}\right)$, recovery period $\left(T_{9}-T_{12}\right)$. HR in group DEX was significantly lower than Group MDZ $((P<0.001)$. The time scale is not linear.

of fentanyl $1 \mu \mathrm{g} / \mathrm{kg}$.

Hemodynamics, including heart rate (HR), systolic blood pressure (SBP), and diastolic blood pressure (DBP), as well as oxygen saturation and RSS scores, were recorded every 10 minutes during infusion $\left(\mathrm{T}_{0}-\mathrm{T}_{7}\right)$, at the end of operation $\left(\mathrm{T}_{8}\right)$ and then every 15 minutes for 1 hour in the recovery room $\left(\mathrm{T}_{9}-\mathrm{T}_{12}\right)$. After surgery, continuous epidural administration of $0.25 \%$ bupivacaine $2 \mathrm{~mL} / \mathrm{hr}$ with fentanyl 20 $\mu \mathrm{g} / \mathrm{hr}$ was used for pain relief. The time to get return to RSS score 2 after stopping infusion was measured as a recovery time. The primary outcome measure of this study was the patient and chief surgeon satisfaction scores using NRS from zero to 10 (zero being least satisfied and 10 most satisfied).

\section{Statistical considerations}

Descriptive statistics are summarized as mean \pm standard, whereas categorical variables are expressed in percentages. Analysis of variance (ANOVA) with repeated measures was used to study the differences of continuous variables between the two groups. Categorical variables were analyzed with chi-square test. All analysis was done by SPSS 13 for Windows. A P value $\leq 0.05$ was considered significant. This study was significantly powered to $10 \%$ difference in the proportion of patients with a RSS score of $<3$ ( 1 - 6 scale) with an $\alpha$ of 0.05 and a $\beta$ of 0.20 .

\section{Results}

One hundred and forty patients were enrolled into the study between April 2009 and March 2010. Seven patients were excluded for failing to catheterize the epidural space; nine patients were excluded for being diagnosed gynecologic cancer

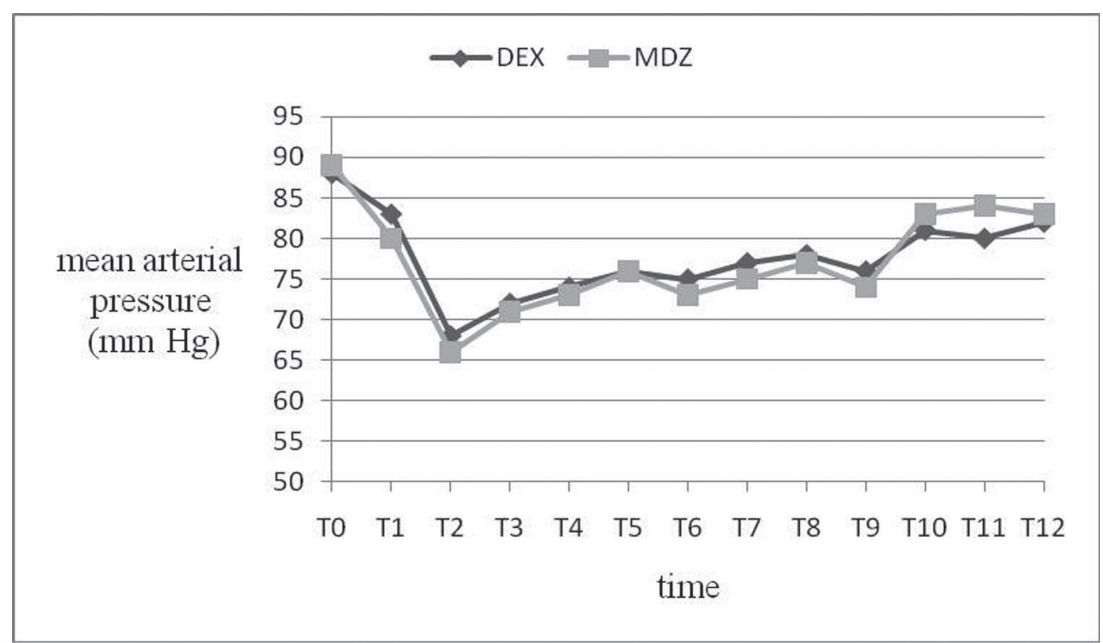

Figure 2. Mean artery pressure (MAP, $\mathrm{mmHg}$ ) was similar between groups (all $\mathrm{P}>0.05)$. 


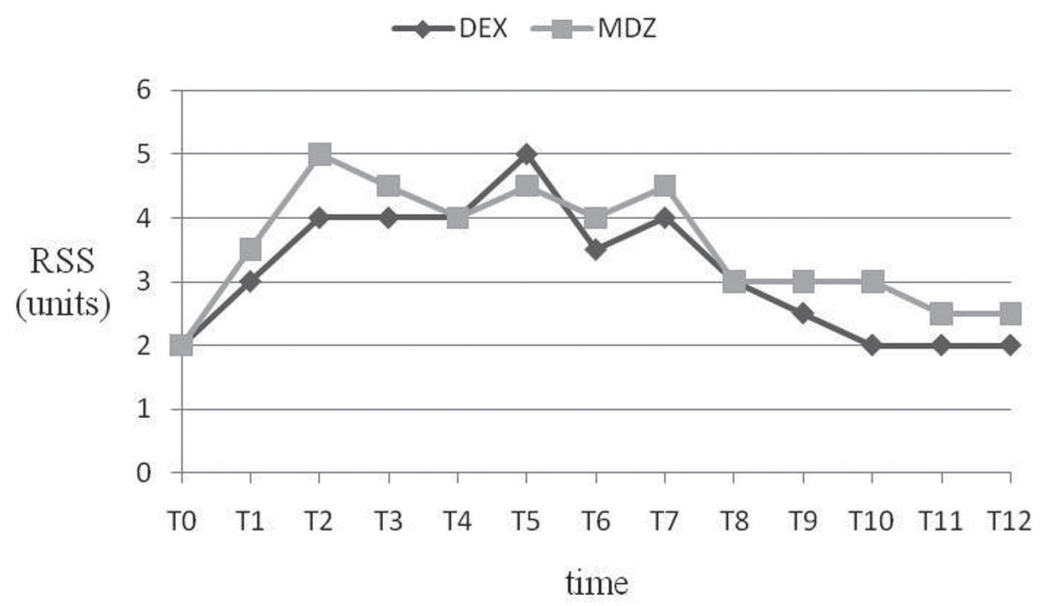

Figure 3. Ramsay Sedation Scale (RSS) score (units) was similar between groups (all P > 0.05).

by intraoperative pathology (turned to general anesthesia). In total, 124 patients were evaluable for outcomes- 63 receiving MID and 61 receiving DEX. The patients' characteristics were similar between the two groups (Table 1).

The patients who had received DEX for sedation during the surgical procedure had significantly reduced fentanyl needs and had no respiratory depression (Table 1). The number of patients who suffered bradycardia was significantly larger in the DEX group (Table 1). Patients and surgeons satisfaction scores were similar between groups and most would choose the same intravenous sedation for a similar procedure in the future, and there was no difference in time to consciousness recovery (Table 1).

Heart rate decreased significantly during dexmedetomidine administration (Fig. 1). MAP was significantly reduced during the intraoperative period in two groups, and the reduction did not show significant differences between the two groups (Fig. 2). Sedation scores were similar between groups during surgical procedures (Fig. 3), but BIS were significantly lower in group DEX during surgical procedures (Fig. 4 ).

\section{Discussion}

Our study demonstrates that dexmedetomidine can provide comparable sedation when compared to midazolam for gynecologic surgery under epidural anesthesia. A lower heart rate and no respiratory depress, as well as easy wake-up, can be achieved by using dexmedetomidine.

Bolus administration of sedative cannot provide constant level of sedation. In contrast, continuous infusion can provide constant sedation level but usually prolongs onset time of sedation compared with the intermittent bolus technique [14]. There are many studies to compare the usefulness of continuous infusion of midazolam and dexmedetomidine

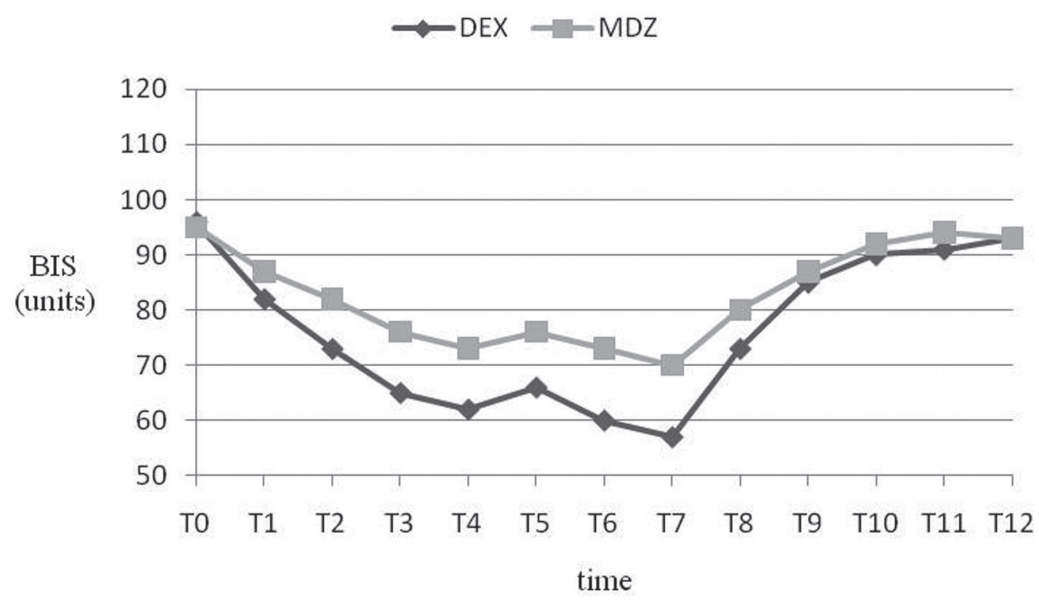

Figure 4. Bispectral index (BIS) values (units) in group DEX was significantly lower than Group MDZ during surgical procedures $(P<0.001)$, and similar during recovery period $(P>0.05)$. 
during regional anesthesia $[15,16]$. However, few studies are available to investigate bolus combined continuous infusion regimen of midazolam or dexmedetomidine. This study proved the regimen can induce rapid and effective sedation during epidural anesthesia.

Cheung CW [17] suggested that dexmedetomidine 0.88 $\mu \mathrm{g} / \mathrm{kg}$ and midazolam $0.07 \mathrm{mg} / \mathrm{kg}$ for patients undergoing local anesthesia to provide a Ramsay Sedation Score greater or equal to four which was felt to be a clinically acceptable level of sedation. In our preliminary study infusing many different doses of midazolam or dexmedetomidine for induction of sedation, we found that $0.05 \mathrm{mg} / \mathrm{kg}$ of midazolam or $0.5 \mu \mathrm{g} / \mathrm{kg}$ of dexmedetomidine might be recommended as an initial infusion dose which provided excellent sedation (RSS $\geq 3$ ) for Patients undergoing gynecologic surgery under epidural anesthesia. Then we chose the initial doses used in the present study. All patients receiving dexmedetomidine reached RSS of three or above, whereas two patients receiving midazolam did not, which inferred that $0.05 \mathrm{mg} / \mathrm{kg}$ of midazolam was insufficient for some patients. The patients receiving midazolam for sedation achieved levels of sedation more rapidly than those receiving dexmedetomidine.

The bispectral index (BIS) is a continuous noninvasive electroencephalographic (EEG) method that has been proposed to monitor the hypnotic state during sedation and anesthesia [18-20]. Triltsch and colleagues [21] found significant correlation for deeply sedated patients whereas no correlation was found in the group with light sedation. But in our study strong correlation was present between BIS and RSS score in light sedation. This controversy might be due to the difference of the patients' age (paediatric vs. adult) or method. Our main finding is that at comparable RASS scores, BIS values were lower with dexmedetomidine sedation than with midazolam. It is widely recognized among anesthesiologists that BIS values between 40 and 60 generally indicates adequate general anesthesia for surgery and the patient cannot be awaken at this time. In our study, however, $68 \%$ of the BIS values were between 40 and 60 during dexmedetomidine sedation, when the RSS score was 3, which is considered an arousable and shallow sedation level. Our results indicate that BIS values do depend on the specific sedative. For example, ketamine paradoxically increases BIS despite a deep clinical level of hypnosis [22-24]. Low BIS values at any given RSS score do not indicate that BIS is "wrong," rather that the characteristics of the 2 drugs differ substantially and that BIS values need to be interpreted in context.

The ideal sedation provides patient comfort and maintenance of spontaneous respiration without altering airway function. Bolus administration of midazolam $0.05 \mathrm{mg} / \mathrm{kg}$ was reported to give enough amnesia and sedation without any adverse effects on hemodynamics and respiration [25]. But in our study 8 of the $63 \mathrm{MDZ}$ patients experienced respiratory depression requiring intervention. This might be due to the more fentanyl consumption or sedative function of epidural anesthesia which had been documented by some investigators $[26,27]$. Dexmedetomidine cannot cause respiratory depression $[28,29]$; this was confirmed in our study. Whilst because of the analgesic effects of dexmedetomidine, patients who had received for sedation during the surgical procedure had significantly reduced analgesic needs (use of fentanyl), this would also reduce the incidence of respiratory depression.

After infusion of dexmedetomidine or midazolam, blood pressure, heart rate and cardiac output decreases slightly. Dexmedetomidine can cause an increase in arterial pressure upon rapid bolus infusion [30]. This is due to direct effects on vascular alpha-1 receptors. This was minimized in our study by slowly infusing the drug, but this will take more time to reach sedation end point when compared to midazolam which also has to be given reasonably slowly as it has a relatively slow time to peak effect [31]. There was not statistically significant in incidence of hypotension between the two groups. But the DEX patients in this study had a significant reduction in HR which occurred most commonly during a bolus or within 10 minutes of the start of an infusion. This finding could be due to: 1) lower basal HR from increased vagal tone; 2) the baroreceptor response of high vascular tone that occurs with the bolus; or 3) high doses and decreased circulating levels of nor epinephrine [32]. The effects of dexmedetomidine on the cardiovascular system may be beneficial in high risk patients [33], but it should be used with caution in patients with bradycardia.

In summary, dexmedetomidine achieved similar levels of sedation to midazolam in gynecologic surgery under epidural anesthesia. Compared with midazolam, it can provide an arousable sedation, an analgesia-sparing effect and without respiratory depression. BIS values are significantly less with dexmedetomidine than with midazolam sedation at comparable RSS scores.

\section{Conflict of Interest Statement}

The authors declare that there are no conflicts of interest.

\section{References}

1. Bailey PL, Pace NL, Ashburn MA, Moll JW, East KA, Stanley TH. Frequent hypoxemia and apnea after sedation with midazolam and fentanyl. Anesthesiology. 1990;73(5):826-830.

2. Bloor BC, Ward DS, Belleville JP, Maze M. Effects of intravenous dexmedetomidine in humans. II. Hemodynamic changes. Anesthesiology. 1992;77(6):1134-1142.

3. Murrell JC, Hellebrekers LJ. Medetomidine and dexmedetomidine: a review of cardiovascular effects and an- 
tinociceptive properties in the dog. Vet Anaesth Analg. 2005;32(3):117-127.

4. Martin E, Ramsay G, Mantz J, Sum-Ping ST. The role of the alpha2-adrenoceptor agonist dexmedetomidine in postsurgical sedation in the intensive care unit. J Intensive Care Med. 2003;18(1):29-41.

5. Ebert TJ, Hall JE, Barney JA, Uhrich TD, Colinco MD. The effects of increasing plasma concentrations of dexmedetomidine in humans. Anesthesiology. 2000;93(2):382-394.

6. Hall JE, Uhrich TD, Barney JA, Arain SR, Ebert TJ. Sedative, amnestic, and analgesic properties of smalldose dexmedetomidine infusions. Anesth Analg. 2000;90(3):699-705

7. Herr DL. Phase IIIB, multi-center, open label, randomized study comparing the safety/efficacy of dexmedetomidine to propofol, for ICU sedation after CABG surgery [abstract]. Crit Care Med 2000; 28:A124.

8. Mantz J, Goldfarb G, Lehot J-J, et al. Dexmedetomidine efficacy for ICU postoperative sedation [abstract]. Anethesiology 1999; 91:A197.

9. Jaakola ML, Salonen M, Lehtinen R, Scheinin H. The analgesic action of dexmedetomidine--a novel alpha 2-adrenoceptor agonist--in healthy volunteers. Pain. 1991;46(3):281-285.

10. Venn RM, Bradshaw CJ, Spencer R, Brealey D, Caudwell E, Naughton C, Vedio A, et al. Preliminary UK experience of dexmedetomidine, a novel agent for postoperative sedation in the intensive care unit. Anaesthesia. 1999;54(12):1136-1142.

11. Aho MS, Erkola OA, Scheinin H, Lehtinen AM, Korttila KT. Effect of intravenously administered dexmedetomidine on pain after laparoscopic tubal ligation. Anesth Analg. 1991;73(2):112-118.

12. Venn RM, Hell J, Grounds RM. Respiratory effects of dexmedetomidine in the surgical patient requiring intensive care. Crit Care. 2000;4(5):302-308.

13. Ramsay MA, Savege TM, Simpson BR, Goodwin R. Controlled sedation with alphaxalone-alphadolone. $\mathrm{Br}$ Med J. 1974;2(5920):656-659.

14. White PF. Use of continuous infusion versus intermittent bolus administration of fentanyl or ketamine during outpatient anesthesia. Anesthesiology. 1983;59(4):294300 .

15. Ghouri AF, Ruiz MA, White PF. Effect of flumazenil on recovery after midazolam and propofol sedation. Anesthesiology. 1994;81(2):333-339.

16. White PF, Negus JB. Sedative infusions during local and regional anesthesia: a comparison of midazolam and propofol. J Clin Anesth. 1991;3(1):32-39.

17. Cheung CW, Ying CL, Chiu WK, Wong GT, Ng KF, Irwin MG. A comparison of dexmedetomidine and midazolam for sedation in third molar surgery. Anaesthesia. 2007;62(11):1132-1138.
18. Rampil IJ. A primer for EEG signal processing in anesthesia. Anesthesiology. 1998;89(4):980-1002.

19. Glass PS, Bloom M, Kearse L, Rosow C, Sebel P, Manberg P. Bispectral analysis measures sedation and memory effects of propofol, midazolam, isoflurane, and alfentanil in healthy volunteers. Anesthesiology. 1997;86(4):836-847.

20. Liu J, Singh H, White PF. Electroencephalographic bispectral index correlates with intraoperative recall and depth of propofol-induced sedation. Anesth Analg. 1997;84(1):185-189.

21. Triltsch AE, Nestmann G, Orawa H, Moshirzadeh M, Sander M, Grosse J, Genahr A, et al. Bispectral index versus COMFORT score to determine the level of sedation in paediatric intensive care unit patients: a prospective study. Crit Care. 2005;9(1):R9-17.

22. Hirota K, Kubota T, Ishihara H, Matsuki A. The effects of nitrous oxide and ketamine on the bispectral index and 95\% spectral edge frequency during propofol-fentanyl anaesthesia. Eur J Anaesthesiol. 1999;16(11):779783.

23. Hans P, Dewandre PY, Brichant JF, Bonhomme V. Comparative effects of ketamine on Bispectral Index and spectral entropy of the electroencephalogram under sevoflurane anaesthesia. Br J Anaesth. 2005;94(3):336340.

24. Recart A, Gasanova I, White PF, Thomas T, Ogunnaike B, Hamza M, Wang A. The effect of cerebral monitoring on recovery after general anesthesia: a comparison of the auditory evoked potential and bispectral index devices with standard clinical practice. Anesth Analg. 2003;97(6):1667-1674.

25. Nishiyama T, Hirasaki A, Odaka Y, et al. Midazolam sedation during spinal anesthesia: Optimal dosage. J Jpn Soc Clin Anesth 1994; 14:257-262.

26. Ishiyama $\mathrm{T}$, Kashimoto $\mathrm{S}$, Oguchi $\mathrm{T}$, Yamaguchi $\mathrm{T}$, Okuyama K, Kumazawa T. Epidural ropivacaine anesthesia decreases the bispectral index during the awake phase and sevoflurane general anesthesia. Anesth Analg. 2005;100(3):728-732, table of contents.

27. Hodgson PS, Liu SS, Gras TW. Does epidural anesthesia have general anesthetic effects? A prospective, randomized, double-blind, placebo-controlled trial. Anesthesiology. 1999;91(6):1687-1692.

28. Grant SA, Breslin DS, MacLeod DB, Gleason D, Martin G. Dexmedetomidine infusion for sedation during fiberoptic intubation: a report of three cases. J Clin Anesth. 2004;16(2):124-126.

29. Avitsian R, Lin J, Lotto M, Ebrahim Z. Dexmedetomidine and awake fiberoptic intubation for possible cervical spine myelopathy: a clinical series. J Neurosurg Anesthesiol. 2005;17(2):97-99.

30. Peden CJ, Cloote AH, Stratford N, Prys-Roberts C. The effect of intravenous dexmedetomidine premedication 
on the dose requirement of propofol to induce loss of consciousness in patients receiving alfentanil. Anaesthesia. 2001;56(5):408-413.

31. Smith MT, Eadie MJ, Brophy TO. The pharmacokinetics of midazolam in man. Eur J Clin Pharmacol. 1981;19(4):271-278.

32. Jorden VS, Pousman RM, Sanford MM, Thorborg PA,
Hutchens MP. Dexmedetomidine overdose in the perioperative setting. Ann Pharmacother. 2004;38(5):803807.

33. Wijeysundera DN, Naik JS, Beattie WS. Alpha-2 adrenergic agonists to prevent perioperative cardiovascular complications: a meta-analysis. Am J Med. 2003;114(9):742-752. 